Images du travail, travail des images

$9 \mid 2020$

L'apprentissage et l'enseignement professionnel en images

\title{
Usine ou école? Les ateliers du lycée Grandmont de Tours
}

Cédric Perrin

\section{CpenEdition}

\section{Journals}

Édition électronique

URL : http://journals.openedition.org/itti/534

DOI : 10.4000/itti.534

\section{Éditeur}

Université de Poitiers

\section{Référence électronique}

Cédric Perrin, "Usine ou école ? Les ateliers du lycée Grandmont de Tours », Images du travail, travail des images [En ligne], 9| 2020, mis en ligne le 01 septembre 2020, consulté le 14 avril 2021. URL: http://journals.openedition.org/itti/534 ; DOI : https://doi.org/10.4000/itti.534

Ce document a été généré automatiquement le 14 avril 2021

Images du travail, travail des images 


\section{Usine ou école ? Les ateliers du lycée Grandmont de Tours}

\section{Cédric Perrin}

Photographie : Vue intérieure des ateliers du lycée Grandmont, Archives du lycée Grandmont.

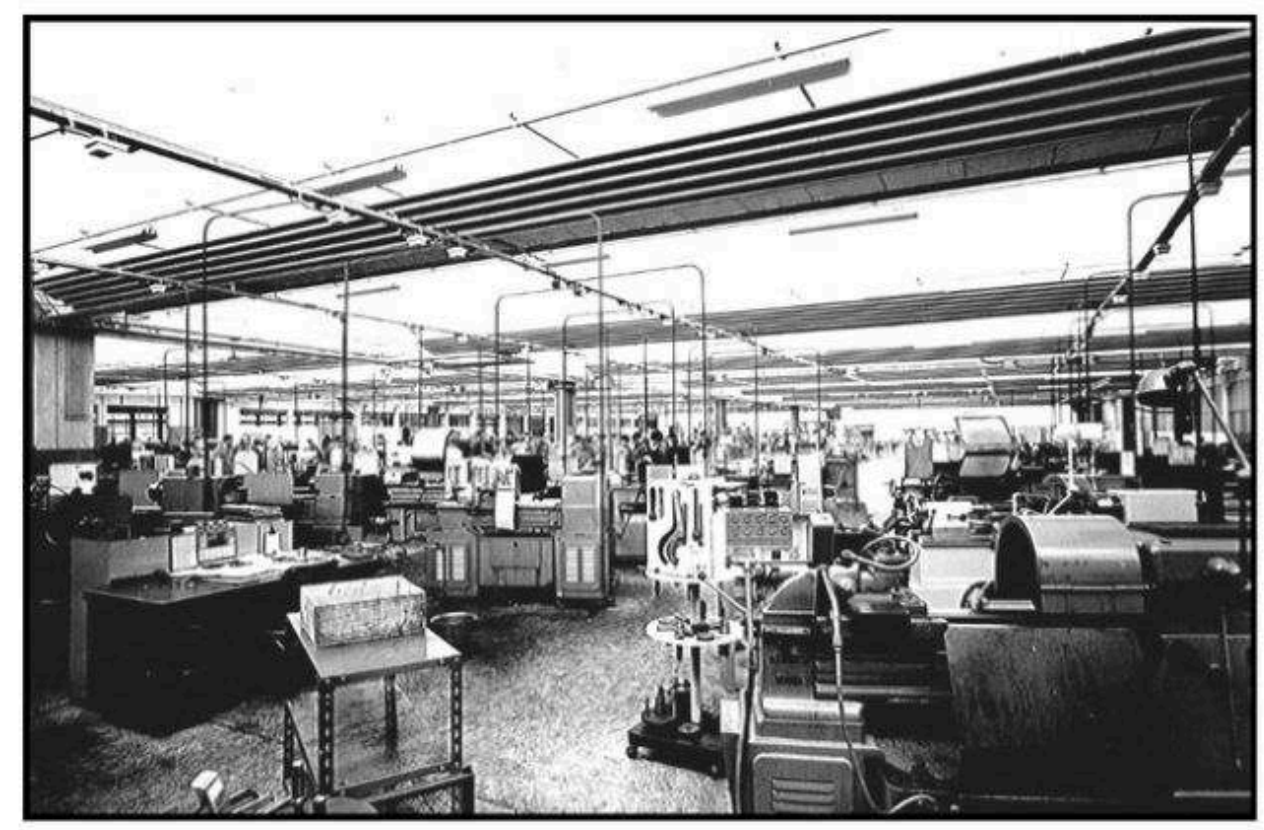

Cette photographie en noir et blanc provient des archives du lycée Grandmont dont elle montre l'intérieur des ateliers. L'auteur n'est pas connu. Elle a été prise peu après l'ouverture du lycée, officiellement inauguré en 1963 mais qui accueille ses premiers élèves dès 1959. Installé dans le vaste parc d'un ancien prieuré situé au sud de Tours, il est d'abord pensé pour soulager les quatre établissements secondaires de la ville, dont les effectifs croissent rapidement, avant que le projet n'intègre l'enseignement technique (Perrin, 2017). Prévu pour une capacité de 2000 élèves (vite dépassée), il est deux fois plus grand que les lycées du centre et il fait partie des très grands lycées, peu 
nombreux, que l'État a construit dans cette période. Il demeure le plus grand lycée de l'académie d'Orléans-Tours et l'un des plus grands du pays.

2 Lycée technique, moderne et classique, il témoigne de la «mise en école» de l'enseignement technique, par l'intégration physique de celui-ci dans un établissement secondaire. Impressionnés par la taille du nouveau lycée et la présence des ateliers, les Tourangeaux lui collent rapidement le qualificatif d'usine. L'établissement ouvre alors que la décentralisation industrielle installe dans la banlieue tourangelle de grandes usines dont ses ateliers semblent reprendre les normes architecturales, facilit ant l'assimilation des uns aux autres. Un article de La Nouvelle République, le quotidien régional, évoquait Grandmont comme le lycée «aux milles machines-outils ». Dans le même temps, l'enseignement technique est influencé par la modèle de la grande entreprise industrielle, qui s'impose en France après la guerre, et l'attention portée au progrès technique et au renouvellement des machines; ce dont témoigne cette image.

Le photographe s'est arrêté sur le parc des machines qui occupe l'essentiel de la composition. Il est difficile de les compter précisément mais leur alignement le long du couloir qui compose la ligne de fuite, également soulignée par le réseau électrique au plafond, suggère qu'elles se démultiplient à l'infini. Le groupe d'élèves avec leur professeur est relégué à l'arrière-plan et à peine visible. La lumière qui tombe des toits en sheds dans de grandes masses blanches recrée l'atmosphère d'une usine. De toute évidence, ce sont les machines plus que l'enseignement lui-même qui ont retenu l'attention du photographe. L'image reflète le contexte de fascination pour la modernité technique qui caractérise les Trente glorieuses (Pessis C., Topçu S. \& Bonneuil C. (dir.), 2013) et marque de son empreinte l'enseignement technique. Localement, elle participe à la construction du mythe de l'usine qui accompagne l'histoire du lycée Grandmont.

\section{BIBLIOGRAPHIE}

Perrin C. (2017) « La création du lycée Grandmont à Tours (1954-1963) : l'impromptue mise en lycée de l'enseignement technique », Histoire de l'éducation, n¹47, p. 177-197

Pessis C., Topçu S. et Bonneuil C. (dir.), 2013, Une autre histoire des Trente Glorieuses : modernisation, contestations et pollutions dans la France d'après-guerre, Paris, La Découverte.

\section{AUTEUR}

\section{CÉDRIC PERRIN}

Professeur agrégé et docteur en histoire, chercheur associé à l'IDHES (UMR 8533). Il enseigne au lycée Grandmont à Tours et à l'université Evry Paris Saclay. Il travaille sur l'histoire des artisans, de l'apprentissage et de l'enseignement technique. Il a notamment publié : Entre glorification et abandon. L'Etat et les artisans en France (1938-1970), CHEFF, Paris, 2007 ; « L'enseignement professionnel : enjeu des relations État-Artisanat de 1945 aux années 1970 », Artefact, n 3, 2015 ; 
« La création du lycée Grandmont à Tours (1954-1963) : l'impromptue mise en lycée de l'enseignement technique ", Histoire de l'éducation, n 147, 2017 et il a dirigé Grandmont. Un lycée, un lieu, une histoire, Presses de Grandmont, Tours, 2013. 